\title{
Bilateral Brachial Plexus Block Using Chloroprocaine For Surgery Of Bilateral Radial Fractures
}

This article was published in the following Dove Press journal:

Local and Regional Anesthesia

\author{
Chanchal Mangla \\ Hattiyangadi Sangeetha Kamath \\ Joel Yarmush
}

Department of Anesthesiology, New York Presbytarian Brooklyn Methodist Hospital, New York, NY, USA
Correspondence: Chanchal Mangla Department of Anesthesiology, New York Presbyarian Brooklyn Methodist Hospital, 506 Sixth Street, Brooklyn, New York, NY, USA

Tel +I 7187803270

Email drchanchalmangla@gmail.com

\begin{abstract}
We report a case of a 41-year-old male with anticipated difficult airway undergoing a repair of a bilateral radial fracture under bilateral sequential brachial plexus block. Anesthesiologists are reluctant to perform bilateral blocks because of the fear of complications like diaphragmatic paralysis, local anesthetic (LA) toxicity, and pneumothorax. We advise that with the correct application of LA pharmacokinetics, careful patient selection and usage of ultrasound, bilateral blocks can be done safely. We used chloroprocaine as an LA in one of the blocks to reduce the dose required for the more toxic LAs. chloroprocaine's fast metabolism also helped us to prevent the overlapping of peak plasma concentration of different LAs. To our knowledge, this is the first reported case in the literature where chloroprocaine was used for bilateral brachial plexus block.
\end{abstract}

Keywords: brachial plexus block, local anesthetics (LA), chloroprocaine

\section{Introduction}

Bilateral brachial plexus block, due to the associated complications, is usually indicated when patient needs both arms to be operated on at the same time and there is a contraindication to general anesthesia. With bilateral brachial plexus blocks, there is a concern about local anesthetic (LA) toxicity, phrenic nerve palsy and pneumothorax. Ultrasound has made it possible to use minimal amounts of LA medication for the peripheral nerve block, thus avoiding LA toxicity while performing more than one block at the same time. It is very important to have the knowledge of pharmacokinetics of the LAs, their toxic levels, and individual susceptibility while performing bilateral blocks to avoid the above mentioned complications.

\section{Case Description}

A 41-year-old healthy male with bilateral comminuted radial fractures after a fall from a bike was scheduled to have open reduction and internal fixation of the fractures. Previously he had a bad experience with general anesthesia, a severe sore throat, so he chose not to have general anesthesia this time. On examination, he was 185 centimeters tall and weighed 68 kilograms. He had an anticipated difficult airway due to orofacial swelling from the sustained trauma. Hence, regional anesthesia with a bilateral brachial plexus block was chosen. Difficult airway equipment was in the operating room. After placing standard ASA monitors and oxygen via nasal cannula, intravenous access was established in the right foot and $2 \mathrm{mg}$ of midazolam was given intravenously. Right infraclavicular brachial plexus block was performed under ultrasound guidance and nerve stimulator and $15 \mathrm{ml}$ of $3 \%$ chloroprocaine, $2 \mathrm{ml}$ 
sodium bicarbonate, $100 \mathrm{mcg}$ of epinephrine 1:10,000 and $15 \mathrm{ml}$ of $0.5 \%$ bupivacaine was given after negative aspiration as intermittent boluses. The right arm surgery was completed in two and a half hours. The left supraclavicular block was then carried out and $15 \mathrm{~mL}$ of $2 \%$ lidocaine, $2 \mathrm{ml}$ sodium bicarbonate, $100 \mathrm{mcg}$ of epinephrine 1:10,000 and $15 \mathrm{ml}$ of $0.5 \%$ bupivacaine was given. Throughout the surgery propofol infusion was given intravenously at the rate of $25 \mathrm{mcg} / \mathrm{kg} /$ minute for sedation. No intravenous analgesics were required for the surgery and no anesthetic complications were noted. The patient was followed up postoperatively after 24 hours and normal motor and sensory functions were present in both arms.

\section{Discussion}

Phrenic nerve palsy, pneumothorax and LA toxicity are the main concerns while doing bilateral brachial plexus blocks, along with risk of failure because of the reduced amount of LA used and discomfort to the patient with bilateral arm motor block. We spaced our blocks to avoid overlapping of the peak plasma concentration of LAs, thus avoiding toxicity. The second block was done immediately after the surgery was finished on the first arm which gave us more than two hours between the blocks. Also the usage of ultrasound and epinephrine allowed us to reduce the dose of LA used.

We used chloroprocaine in our first block, which is metabolized quickly and the plasma concentration would be minimal by the time of the second block.

We chose to do one block below the clavicle and other above the clavicle, thus reducing the risk of phrenic nerve palsy as the risk decreases with below clavicle blocks. We reduced the volume of LA in each block to a total of $30 \mathrm{~mL}$ to reduce the risk of LA toxicity, usually we use around 40 $\mathrm{mL}$ in a block. We used the combination of a faster acting LA like chloroprocaine and lidocaine with a longer acting LA like bupivacaine, thus avoiding higher doses of the toxic and longer acting LA (bupivacaine). We also used epinephrine with the LA to slow the absorption of LA, and also to detect any inadvertent intravascular injection. The total dose of LAs used in our patient were $450 \mathrm{mg}$ of chloroprocaine, $300 \mathrm{mg}$ of lidocaine and $150 \mathrm{mg}$ of bupivacaine, which were well below the maximum recommended dosages and were also given over time intervals. In case the regional blocks failed, we had difficult airway equipment for general anesthesia as a backup plan.

Phrenic nerve palsy causing hemidiaphragmatic paralysis is the major concern while performing a brachial plexus block, it may even occur in $100 \%$ of cases with interscalene block. There is a risk of reduction in Forced vital capacity (FVC) by up to $60 \%$ with total diaphragmatic paralysis in cases of bilateral blocks, ${ }^{1}$ hence bilateral interscalene blocks are not recommended. Renes et al reported that use of ultrasound reduces the incidence of hemidiaphragmatic paralysis by $95 \%$ by allowing direct visualization of phrenic nerve, thus avoiding LA around the nerve and by reducing the amount of LA needed. ${ }^{2}$ In the approach below the cricoid cartilage, the phrenic nerve block depends on the administered volume. ${ }^{3}$ Sen et al reported a case series of continuous bilateral brachial plexus block without complications. ${ }^{4}$ Phrenic nerve palsy can occur with infraclavicular block $(25 \%)$ but much less frequently than supraclavicular $(50 \%)$ and interscalene block $(100 \%){ }^{5}$

Incidence of pneumothorax after the supraclavicular approach is $0.5-6.1 \%{ }^{6}$ This may be reduced with expertise and the use of ultrasound. It has also been reported after an interscalene and infraclavicular approach. Patients may remain asymptomatic for 6-12 hours after a pneumothorax if there is no use of positive pressure. Careful patient selection can avoid major respiratory compromise in case of complications.

The incidence of seizure after peripheral nerve block is 0.01 to $0.2 \%{ }^{1}$ The potential for systemic reactions is related to peak free concentration of LA, which in turn depends on the amount of LA injected, the physical characteristics of LA, the use of epinephrine, and blood flow to the injection site. Knowledge of minimal effective doses, maximum allowable doses, and patient-related factors are helpful in reducing LA toxicity. The maximum allowable doses for LAs are difficult to determine and are based on animal studies and case reports, there are no prospective studies on human subjects. Doses appear to be different according to different publications and are rough guidelines, it does not take into account the site or technique of LA administered or patient-related factors. Continuous catheter techniques have shown to produce less incidence of toxicity as it allows titrated doses of LA, thus maintaining lower peak plasma concentrations. ${ }^{1}$ Box 1 shows the factors that need to be considered while carrying out a bilateral brachial plexus block.

There are limited reports of the use of chloroprocaine for peripheral nerve blocks in the literature. Cunningham et al had reported the use of chloroprocaine and bupivacaine for axillary blocks. ${ }^{7}$ The combination of chloroprocaine with bupivacaine has been used in our institution for brachial plexus blocks and has been shown to have a faster onset 
Box I Factors To Consider For Bilateral Brachial Plexus Block

\begin{tabular}{|l|}
\hline Use smaller dose of LA with ultrasound guidance and expertise and consider pharmacokinetics of individual LAs. \\
\hline Consider individual susceptibility to LA doses like old age, pregnancy, hypoxemia, acidemia, lower weight, and organ dysfunction. \\
\hline Consider one brachial plexus block above the clavicle and the other below the clavicle. \\
\hline Spacing of blocks to prevent concurrent peak absorption of drug. \\
\hline Consider continuous catheter technique to reduce toxic concentration and allow titration. \\
\hline Use of less toxic LAs, such as lidocaine/mepivacaine/chloroprocaine along with longer acting LAs, such as ropivacaine/levobupivacaine/bupivacaine \\
\hline Use of adrenaline to slow absorption and detection of intravascular injection.
\end{tabular}

Abbreviations: LA = Local Anesthetic; FVC = Forced Vital Capacity.

than the lidocaine and bupivacaine combination. ${ }^{8}$ Use of chloroprocaine has not been reported for bilateral brachial plexus blocks. When used in combination (shorter and longer acting LAs), the toxicities are not independent of each other, so the maximum recommended dose of each LA should not be used. ${ }^{9}$ Recently, some studies and reviews have shown no advantages of mixing LAs as it does not speed up the onset of action or duration. ${ }^{10}$ Moreover with mixing, it is difficult to determine the safe doses of LA since the onset of action, dose, and peak plasma concentration of each LA are variable. Toxicity cannot be summed up by simply adding together the dose limits of each specific LA.

We should avoid doing bilateral interscalene blocks because of the risk of bilateral diaphragmatic paralysis, though Mejia et al has reported a successful bilateral interscalene block. ${ }^{11}$

A bilateral supraclavicular block should be avoided, especially if ultrasound is not available, because of the associated risk of diaphragmatic paralysis and pneumothorax. ${ }^{12}$

Doing a combination of brachial plexus block (above and below the clavicle) reduces the risks of the above-mentioned complications. We should also consider doing a peripheral nerve block or forearm block on one side if the surgery site allows, but it has to be accompanied by either general anesthesia or deep sedation to prevent the tourniquet pain. The addition of general anesthesia or deep sedation has been shown to aggravate LA induced toxicity/cardiovascular depression. ${ }^{12}$

\section{Conclusion}

Bilateral brachial plexus blocks are relatively contraindicated due to the possible complications such as bilateral diaphragmatic paralysis, and LA toxicity, as well as being uncomfortable for the patient, and time consuming. But in exceptional situations, after a thoroughly performed consideration process, this bilateral approach could be an option.

\section{Consent Statement}

As the patient has been lost to follow up, patient consent for publication of this case was not possible. The details have been sufficiently anonymized not to cause harm to the patient.

\section{Disclosure}

The authors report no conflicts of interest in this work.

\section{References}

1. Holborow J, Hocking G. Regional Anesthesia for bilateral upper limb surgery: a review of challenges and solutions. Anesth Intensive Care. 2010;38:250-258. doi:10.1177/0310057X1003800205

2. Renes SH, Spoorman HH, Gielen MJ, et al. Hemidiaphragmatic paresis can be avoided in ultrasound guided supraclavicular brachial plexus block. Reg Anesth Pain Med. 2009;36:595-599

3. Kessler J, Schafhalter-zoppoth GAT. An ultrasound study of the phrenic nerve in the posterior cervical triangle. Implications for the interscalene brachial plexus block. Reg Anesth Pain Med. 2008;33:545550.

4. Sen S, Franklin M, Koyyakamudi V, et al. Continuous bilateral brachial plexus blockage for acute pain control in patients with bilateral upper extremity traumatic injuries: a review of five cases. Clin Med Rev Case Rep. 2017;4:163. doi:10.23937/2378-3656/1410163

5. Macfarlene A, Anderson K. Infraclavicular brachial plexus block. $\mathrm{Br} J$ Anaesth. 2009;9(5):139-143.

6. Neal JM, Hebl JR, Gerancher JC, et al. Brachial plexus anesthesia. Essentials of our current understanding. Reg Anesth Pain Med. 2002;27:402-428.

7. Cunningham NL, Kaplan JA. A rapid onset long acting regional anesthetic technique. Anesthesiology. 1974;41:509-511. doi:10.109 7/00000542-197411000-00020

8. Jafari S, kalstein A, Nasrulla HM, et al. A randomized, prospective, double blond trial comparing $3 \%$ chlorprocaine followed by $0.5 \%$ bupivacaine to $2 \%$ lidocaine followed bt $0.5 \%$ bupivacaine for interscalene brachial plexus block. Anesth Anal. 2018;107(5):1746-1750. doi:10.1213/ane.0b013e318185cd5e 
9. Yaddanapudi S. Prevention of local anesthetic systemic toxicity. $J$ Anaesthesiol Clin Pharma Col. 2011;27(4):438-439. doi:10.4103/ 0970-9185.86566

10. Sepehripour S, Dheansa B. Is there an advantage in onset of action with mixing lignocaine and bupivacaine. Jpras. 2017;70(12):1782.

11. Mejia-Terrazaz GE, Gardeni-Juarez Mde A, Limon-Muniz M, et al. Bilateral brachial plexus block. Case report and systemic review. Cir Cir. 2015;83(4):312-318. doi:10.1016/j.circir.2015.05.018
12. Franci CD, Salahuddin Z, Rafizad A. Bilateral brachial plexus block. Anesth Anal. 2004;98(2):518-520. doi:10.1213/01.ANE.0000097441. 67236.33

\section{Publish your work in this journal}

Local and Regional Anesthesia is an international, peer-reviewed, open access journal publishing on the development, pharmacology, delivery and targeting and clinical use of local and regional anesthetics and analgesics. The journal welcomes submitted papers covering original research, basic science, clinical studies, reviews \& evaluations, guidelines, expert opinion and commentary, case reports and extended reports. The manuscript management system is completely online and includes a very quick and fair peer-review system, which is all easy to use. Visit http://www.dovepress.com/testimonials. php to read real quotes from published authors. 